\title{
Surfactant-Associated Protein B Kinetics In Vivo in Newborn Infants by Stable Isotopes
}

\author{
PAOLA COGO, ALDO BARITUSSIO, FEDERICA ROSSO, ANTONINA GUCCIARDI, \\ VINCENZO MORETTI, TAMARA BADON, ELENA DUNER, LUC ZIMMERNANN, AND \\ VIRGILIO P. CARNIELLI \\ Department of Pediatrics [P.C., F.R., A.G., T.B.], University of Padova, 35128 Padova, Italy; Department \\ of Medical and Surgical Sciences [A.B., E.D.], Clinica Medica I, University of Padova, 35128 Padova, \\ Italy; Pharmacy [V.M.], Salesi Children Hospital, Ancona, Italy; Department of Pediatrics [L.Z.], \\ Maastricht University, 6202 AZ Maastrict, The Netherlands; and Division of Neonatology [V.P.C.], Salesi \\ Children Hospital, Ancona, Italy
}

\begin{abstract}
ABSTR
Surfactant-associated protein B (SP-B) is critical to the bio-
physical function of pulmonary surfactant. No information is
available on SP-B synthesis and kinetics in humans. We admin-
istered a 24-h i.v. infusion of ${ }^{13} \mathrm{C}$-valine as metabolic precursor
of SP-B to six newborn infants (weight $3.5 \pm 0.5 \mathrm{~kg}$; age $12 \mathrm{~d}$,
range $1-43 \mathrm{~d})$. Three of the study infants also received i.v.
${ }^{2} \mathrm{H}-$ palmitate to label surfactant disaturated phosphatidylcholine
(DSPC). SP-B and DSPC were isolated from tracheal aspirates,
and their respective ${ }^{13} \mathrm{C}$ and ${ }^{2} \mathrm{H}$ enrichments were measured by
gas chromatography-mass spectrometry. SP-B kinetics was mea-
sured successfully in all six infants. SP-B median (range) frac-
tional synthesis rate was $30 \%$ per day (20-78\% per day), secre-
tion time was $4.5 \mathrm{~h}(1-9 \mathrm{~h})$, time to peak was $24 \mathrm{~h}(12-36 \mathrm{~h})$, and
half-life was $21 \mathrm{~h}(8-35 \mathrm{~h})$. The ascending part of the SP-B
\end{abstract}
Surfactant-associated proteins B and C (SP-B and SP-C, respectively) represent $<5 \%$ of surfactant by weight, but they play a pivotal role in maintaining surfactant function (1). Surfactant deficiency is the hallmark of respiratory distress syndrome in preterm infants. In respiratory distress syndrome, there is a reduced amount of phospholipids (2) and of SP-B and SP-C (3). The key role of SP-B became evident in congenital SP-B deficiency, which is characterized by severe respiratory failure leading ultimately to death unless lung transplant is performed $(1,4)$. To date, there are no data on SP-B kinetics in humans, but information is available in adult and newborn animals, in which radioactive labels can be used. These studies showed differences in SP-B clearance and kinetics depending on animal species and postnatal age (5-7).

Received April 12, 2004; accepted September 2, 2004

Correspondence: Paola E. Cogo M.D., Department of Pediatrics, University of Padova, Via Giustiniani 3, 35128 Padova, Italy; e-mail: cogo@pediatria.unipd.it.

This study was conducted with core funding of the laboratory of Nutrition and Metabolism of the Department of Pediatrics, University of Padova, Italy, and it was also supported by the Foundation "NeoMed Onlus," Ancona, Italy.

DOI: 10.1203/01.PDR.0000155755.27716.04 kinetic curve was similar to the DSPC curve, suggesting similar secretion pathways. SP-B half-life seemed to be shorter than DSPC half-life. These results agree with existing animal data. We conclude that the measurement of SP-B kinetics is feasible in vivo in humans by stable isotope technology. (Pediatr Res 57: 519-522, 2005)

Abbreviations
DSPC, disaturated-phosphatidylcholine
FSR, fractional synthesis rate
SP-B, surfactant-associated protein B
SP-C, surfactant-associated protein C
ST, secretion time
TA, tracheal aspirate

We recently described methods based on stable isotopes to measure surfactant disaturated-phosphatidylcholine (DSPC) kinetics in humans $(8,9)$. The main objective of this study was to demonstrate the feasibility of measuring SP-B kinetics in vivo in newborn infants by means of stable isotopes.

\section{METHODS}

SP-B kinetics was studied in six infants (Table 1) who were admitted to the neonatal intensive care unit, Department of Paediatrics, University of Padua. Inclusion criteria were 1) gestational age $>37 \mathrm{wk}, 2$ ) respiratory failure requiring endotracheal intubation for an estimated length of at least $48 \mathrm{~h}, 3$ ) arterial and venous lines placed for clinical monitoring, and 4) written parental consent. Exclusion criteria were congenital chromosomal abnormalities and exogenous surfactant given at $<48 \mathrm{~h}$ before study start. The local Ethics Committee approved the study protocol.

All patients received a $24-\mathrm{h}$ constant i.v. infusion of $2 \mathrm{mg} / \mathrm{kg} / \mathrm{h} 1{ }^{13} \mathrm{C}$ valine (Mass Trace, Woburn, MA), dissolved in normal saline, while they were on a lipid-free i.v. infusion. In three infants, we also infused i.v. $0.4 \mathrm{mg} / \mathrm{kg} / \mathrm{h}$ $16,16,16{ }^{2} \mathrm{H}$ palmitic acid (CIL, Andover, MA), associated with human albumin (10).

Blood $(0.6 \mathrm{~mL})$ was drawn at time $0,5: 30,6,12,18$, and $24 \mathrm{~h}$ from the start of the study to determine the isotopic enrichment of plasma valine and of palmitic acid at plateau. Blood samples were placed in tubes that contained 
Table 1. Clinical characteristics of the study infants

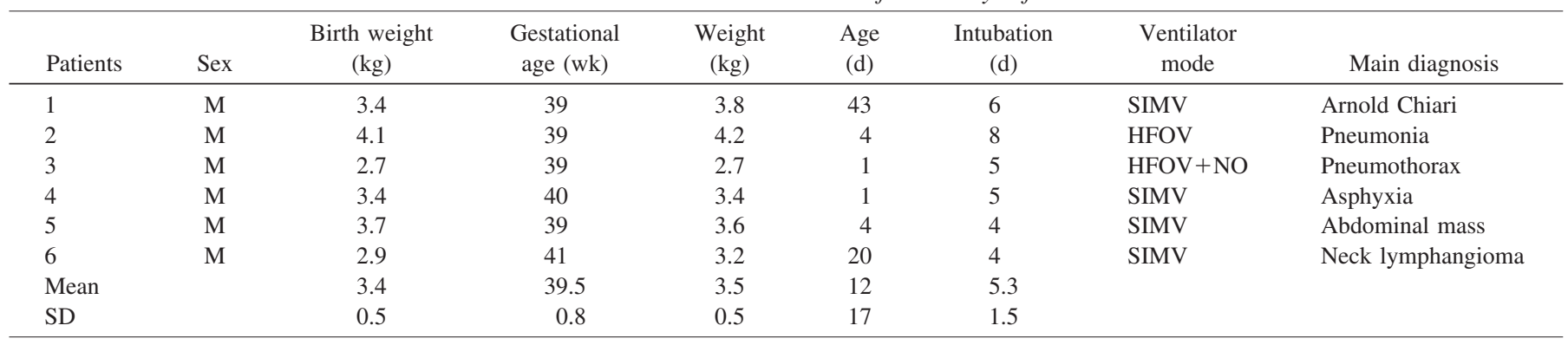

EDTA and centrifuged immediately at $1300 \times g$, and plasma was stored at $-20^{\circ} \mathrm{C}$.

Tracheal aspirates (TAs) were performed according to a standardized procedure as previously described (9), and they were obtained before the start of the isotope(s) infusion, every $6 \mathrm{~h}$, until $72 \mathrm{~h}$ and every $12 \mathrm{~h}$ until extubation or until study day 7. TAs were centrifuged at $150 \times g$ for $10 \mathrm{~min}$, and supernatant was stored at $-80^{\circ} \mathrm{C}$ until analysis.

Production of antiserum anti-SP-B. Surfactant that was obtained from a patient with alveolar proteinosis (6.8 $\mathrm{mg}$ phospholipids) was extracted according to Bligh and Dyer (11). Aliquots that contained $0.5 \mathrm{mg}$ of phospholipids were suspended in chloroform and applied onto columns Bond Elute $\mathrm{NH}_{2}(500$ $\mathrm{mg}$ of resin per column; Varian, Harbor City, CA), and each column was eluted sequentially with $6 \mathrm{~mL}$ of the following mixtures made of chloroform:methanol:acetic acid: 100:0:0, 20:1:0, 9:1:0, 4:1:0, 4:1:0.025, 3:2:0, 1:4:0, and 1:9:0. The 4:1:0 eluates, which contained pure SP-B, were combined and dried under nitrogen. One fourth of SP-B obtained by the method described above was suspended in $0.25 \mathrm{~mL}$ of saline solution by sonication, combined with 0.25 $\mathrm{mL}$ of complete Freund's adjuvant, and injected s.c. into an adult rabbit under light anesthesia. Boosting injections of SP-B in incomplete Freund's adjuvant were done after 1,2, and 3 mo. Serum was obtained by exsanguination after 4 mo. This antiserum recognizes SP-B and Pro-SP-B but does not recognize SP-C. Isolation of DSPC from TA was performed as previously published (9).

Isolation of SP-B from TA. SP-B was isolated with Bond Elute $\mathrm{NH}_{2}$ columns that contained $100 \mathrm{mg}$ of resin (Supelco, Milan, Italy). TA supernatant was extracted according to Bligh and Dyer (11). The chloroform phase was dried under nitrogen, resuspended in chloroform, and applied to a Bond Elute $\mathrm{NH}_{2}$ column that was preconditioned with $3-5 \mathrm{~mL}$ of chloroform. After loading, the columns were eluted sequentially with $3 \mathrm{~mL}$ of the following chloroform/methanol/acetic acid mixtures: 20:1:0, 9:1:0, 4:1:0, 4:1:0.025, $3: 2: 0,1: 4: 0$, and 1:9:0. For studying the elution of surfactant proteins, eluates were dried under nitrogen, solubilized, reduced, separated by PAGE (12), transferred on nitrocellulose, and probed with the antiserum anti-human SP-B and an antiserum anti-SP-C (Fig. 1). Antibodies anti-SP-C were provided by Altana Pharma AG (Konstanz, Germany). Most of SP-B eluted with the mixture 4:1:0, whereas SP-C started to be recovered with the mixture 3:2:0. In a separate experiment, in which the material eluted with the mixture $4: 1: 0$ was separated by PAGE and stained with Coomassie stain, we found only a protein band corresponding to mature SP-B (data not shown).

SP-B eluted from the Bond Elute $\mathrm{NH}_{2}$ column mainly with the 4:1:0 mixture and to a smaller extent with the 4:1:0.025 and 3:2:0 mixtures (Fig. 1). For the purpose of the present study, we analyzed only SP-B eluted by the mixture 4:1:0, because this fraction is not contaminated by SP-C (Fig. 1).

To measure the recovery of SP-B in fraction 4:1:0, we administered into the trachea of a 3-d-old rabbit $250 \mu \mathrm{Ci}$ of Trans ${ }^{35} \mathrm{~S}$ Label (ICN Biomedicals, Irvine, CA). After $16 \mathrm{~h}$, the alveolar surfactant was isolated and extracted according to Bligh and Dyer (11). The extract then was fractionated by Sephadex LH60 chromatography $(1 \times 80 \mathrm{~cm}$ column, eluents: chloroform:methanol:0.1 N HCl [47.5:47.5:5]) to isolate ${ }^{35}$ S-labeled SP-B and SP-C. ${ }^{35} \mathrm{~S}$-labeled SP-B was dried down, suspended in chloroform, mixed with 150 $\mu \mathrm{g}$ of nonlabeled rabbit surfactant extract, and subjected to Bond Elute $\mathrm{NH}_{2}$ chromatography. We recovered in the 4:1:0 eluate $40 \%$ of applied radioactivity. In a companion experiment, only traces of radioactivity were recovered in the 4:1:0 eluate, when ${ }^{35} \mathrm{~S}$-labeled SP-C was applied to a Bond Elute $\mathrm{NH}_{2}$ column.

For studying the incorporation of ${ }^{13} \mathrm{C}$ valine into SP-B (i.e. SP-B kinetics in infants), the SP-B fraction had to be hydrolyzed to free amino acids by $0.5 \mathrm{~mL}$ of $6 \mathrm{~N} \mathrm{HCl}$ for $24 \mathrm{~h}$ at $110^{\circ} \mathrm{C}$ under vacuum condition. Amino acids from acid hydrolysis of SP-B were derivatized into their N-acetyl-n-propyl derivatives (13).

Plasma valine enrichment. Fifty milliliters of plasma EDTA was deproteinized with sulfosalicylic acid $(6 \% \mathrm{wt} / \mathrm{vol})$, and plasma amino acids were
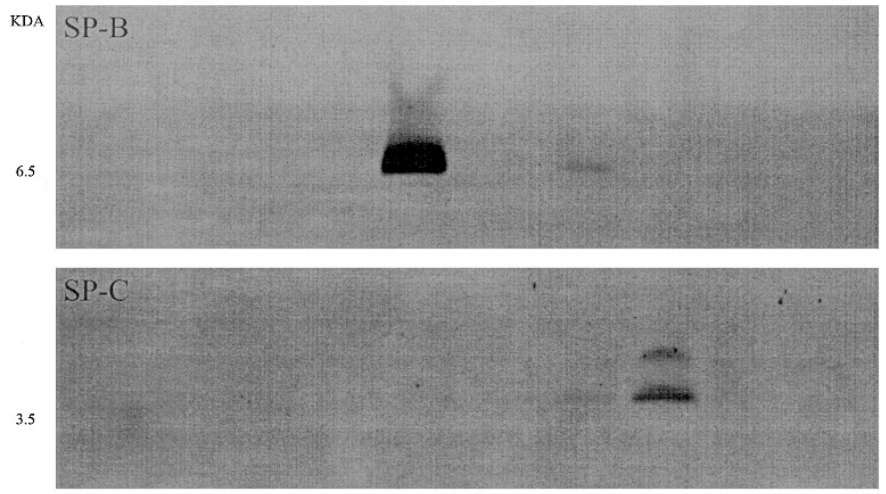

$\begin{array}{lllllllll}\text { Fraction } \mathrm{N}^{\circ} & 2 & 3 & 4 & 5 & 6 & 7 & 8 & 9 \\ \mathrm{C} & 1 & 20 & 9 & 4 & 4 & 3 & 1 & 1 \\ \mathrm{M} & 0 & 1 & 1 & 1 & 1 & 2 & 4 & 9 \\ \mathrm{AA} & 0 & 0 & 0 & 0 & 0.025 & 0 & 0 & 0\end{array}$

Figure 1. Isolation of SP-B. The Bligh and Dyer (12) extract of a BAL sample that contained $150 \mu \mathrm{g}$ of phospholipids was dissolved in chloroform, applied to $100 \mathrm{mg}$ of Bond Elute $\mathrm{NH}_{2}$ column, and eluted with mixtures of chloroform:methanol:acetic acid. Eluates were dried, reduced, separated by PAGE, transferred onto nitrocellulose, and probed with antiserum anti-SP-B (top) or anti-SP-C (bottom).

derivatized according to Husek (14). Free plasma valine enrichment was measured by gas chromatography-mass spectrometry (Voyager, Thermoquest, Milan, Italy).

SP-B valine and DSPC palmitate enrichments. The enrichment of SP-B valine and DSPC palmitate was measured by gas chromatography-isotope ratio-mass spectrometry $(8,10)$. Valine was injected in split less mode and separated on a Ultra2, J\&W capillary column $(25 \mathrm{~m} \times 0.20 \mathrm{~mm} \times 0.33 \mathrm{~mm}$ film thickness; J\&W, Agilent Technologies Italia S.P.A, Cernusco sul Naviglio, Milan, Italy). DSPC palmitate was separated as previously published (8). Results were expressed as mole percentage excess and referred to a calibration curve for both ${ }^{13} \mathrm{C}$ valine and ${ }^{2} \mathrm{H}$ palmitic acid with enrichment values ranging from 0 to $5 \%$ mole percentage excess (8). Each sample was analyzed in triplicate.

DSPC amounts from TA. DSPC amount from TA was determined by gas chromatography as previously described (10).

Calculations. Tissue-bound and alveolar surfactant were regarded as one pool.

Kinetic parameters. Fractional synthesis rate (FSR), secretion time (ST), peak time, and half-life were calculated by using both ${ }^{13} \mathrm{C}$-valine and ${ }^{2} \mathrm{H}-$ palmitate as previously published $(8,10)$. Briefly, FSR was calculated by dividing the slope of the linear increase of the enrichment of DSPC and SP-B by the plasma steady-state enrichment of free ${ }^{2} \mathrm{H}$-palmitate and ${ }^{13} \mathrm{C}$-valine.

ST of DSPC and SP-B was defined as the time lag between the start of the infusion of the precursor and the appearance of the enriched product. This was calculated by plotting the regression line for the linear-increasing part of the enrichment versus time curve and extrapolating it to baseline enrichment.

Peak time is the time of maximum enrichment of surfactant DSPC and SP-B after the start of the isotope infusion. Half-life of DSPC and SP-B was calculated by exponential curve fitting at the final mono-exponential part of the down slope of the enrichment versus time curve.

Clinical variables are expressed as individual values and as mean \pm SD Kinetic data are presented as individual values and group median and range. 

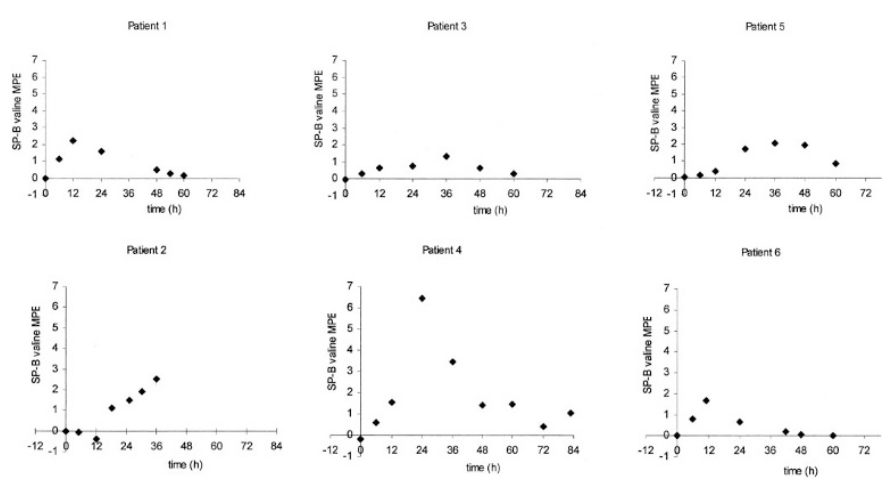

Figure 2. SP-B kinetic curves after a 24 -h infusion of ${ }^{13} \mathrm{C}$ valine in six newborn infants on mechanical ventilation.

\section{RESULTS}

Characteristics of study infants are reported in Table 1 . Patient 2 was intubated at birth for neonatal pneumonia that required fraction of inspired oxygen $>0.40$, high-frequency ventilation, and $100 \mathrm{mg} / \mathrm{kg}$ exogenous surfactant given $96 \mathrm{~h}$ before study start. Patient 3 presented with birth asphyxia, pneumothorax, and pulmonary hypertension that required high-frequency ventilation and nitric oxide for $4 \mathrm{~d}$. All other infants had no lung disease, and they were intubated for major surgery (patient 5 and patient 6 ) or for perinatal asphyxia leading to neurologic failure (patient 4) or for vocal cord paralysis (patient 1). SP-B valine enrichment was measurable in all study infants and in all samples with the exception of patient 2 from $36 \mathrm{~h}$ onward. Figure 2 reports all six SP-B kinetic curves. Individual and mean SP-B kinetic parameters are reported in Table 2.

Median (range) DSPC FSR was $25 \%$ per day (20-28\% per day), ST was $25 \mathrm{~h}(25-35 \mathrm{~h})$, peak time was $42 \mathrm{~h}(36-42 \mathrm{~h})$, and half-life was $35 \mathrm{~h}$ (25-96 h). Figure 3 depicts the enrichment curves of SP-B and DSPC in one study infant. The ascending parts of the SP-B and DSPC curves were similar, whereas SP-B half-life was shorter than that of DSPC in all three patients who received both tracers.

\section{DISCUSSION}

General considerations. In this pilot study, we report for the first time data on SP-B synthesis and kinetics measured by stable isotopes in vivo in humans. Because of the pivotal role played by SP-B in maintaining surfactant function in healthy and diseased lungs (1), we believe that this method will be proved to be important to the understanding of the role of SP-B in human lungs. Our preliminary results indicate that SP-B has a short half-life of $\sim 20 \mathrm{~h}$. This could be due to a rapid turnover, to a less extensive recycling in comparison with surfactant lipids, or to a combination of these mechanisms. If this finding were to be confirmed in a larger number of patients, then we hypothesize that SP-B concentrations may rapidly become critically low in case of reduced synthesis or of accelerated catabolism.

Analytical considerations. SP-B and SP-C are highly hydrophobic proteins, and their analytical separation is difficult. Their quantitative measurements are troublesome, especially in samples from newborn infants, in whom concentrations could be low. Immunoblotting techniques (3) are not suitable for isotopic enrichment determination because of the possible amino acid contaminations. We therefore chose to isolate SP-B from SP-C and the lipids by sorbent chromatography (15). Besides patient 2, in whom the descending part of the SP-B kinetic curve was not measurable (Fig. 2), we found a coefficient of variation of $<3 \%$ for each SP-B sample measured in triplicate.

We did not find measurable contamination of SP-B by SP-C 1) by immunoblotting (Fig. 1) or 2) by mixing surfactant extracts with SP-C labeled in vivo with ${ }^{35} \mathrm{~S}$ and then performing Bond Elute $\mathrm{NH}_{2}$ chromatography (see "Methods"). The main disadvantage of our method is the time involved in measuring each TA, which is $\sim 2 \mathrm{~d}$. With this limitation in mind and considering results from animal work (5-7) and from our own studies, we decided to process only seven to eight time points for each individual patient. Having obtained data, as depicted in Fig. 2, we suggest that future studies should analyze TA every $6 \mathrm{~h}$ for the first $48 \mathrm{~h}$ and every $12 \mathrm{~h}$ until $72 \mathrm{~h}$.

Our findings compared nicely with animal data. Previous work in mice and rabbits $(5,6,16)$ showed that secretion rate of SP-B was similar to that in DSPC, but clearance rate was different. All of these studies used either i.v. and/or intratracheal radioactive precursors $(5-7,15)$. The longest duration of published studies was $48 \mathrm{~h}$, whereas we studied our patients for up to $5 \mathrm{~d}$. This allowed us to use only one tracer.

Clinical relevance. Low levels of mature SP-B lead to impaired lung function and severe respiratory failure $(1,4,17-$

Table 2. SP-B and DSPC kinetics after 24-h i.v. infusion of $1-{ }^{13} \mathrm{C}$ valine and ${ }^{2} \mathrm{H}$ palmitate

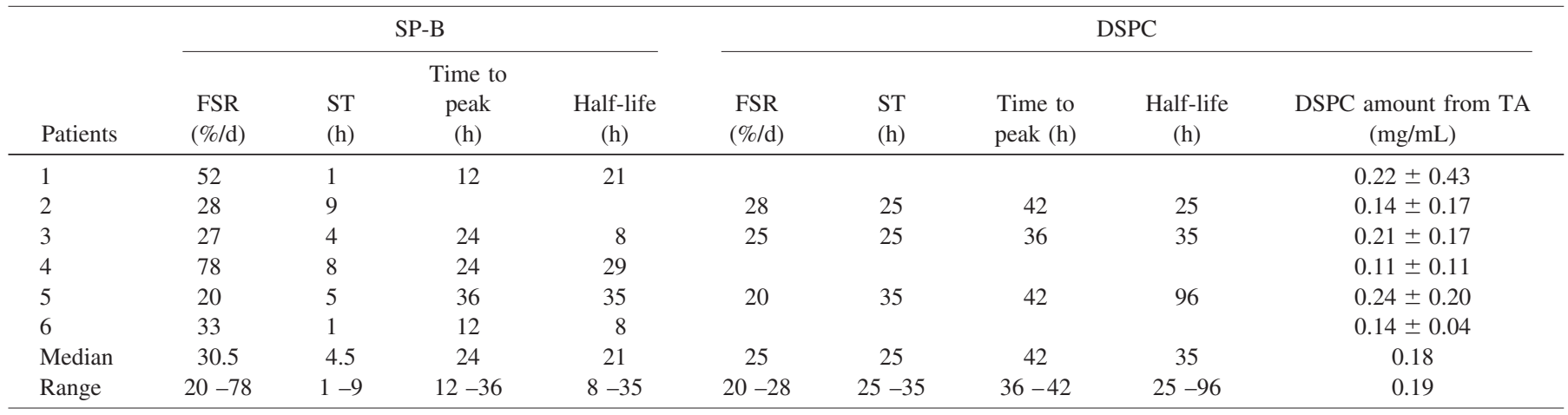




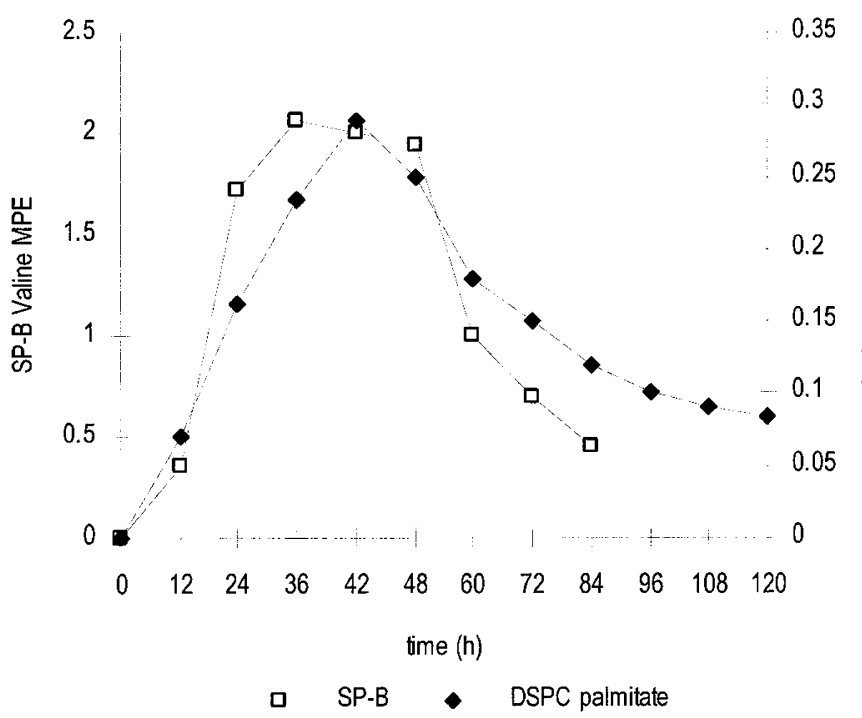

Figure 3. SP-B and DSPC kinetic curves after the simultaneous i.v. administration of ${ }^{13} \mathrm{C}$ valine ( $\square$; left $y$ axis) and ${ }^{2} \mathrm{H}$ palmitate ( $\bullet$; right $y$ axis) in study infant 5 .

20). Thus, measuring SP-B kinetics in vivo in humans will be an irreplaceable tool for identifying clinical situations in which SP-B synthesis may be reduced or its catabolic rate accelerated.

Limitations of the study. The number of patients is definitely too small to make any meaningful clinical consideration. The main message of this article is that SP-B kinetics can be measured in vivo in humans using stable isotope technology and that SP-B and DSPC kinetic studies can be obtained in the same patient. Because Clara cells from the conductive airways are able to synthesize SPs $(21,22)$, further studies will be needed to ascertain differences between surfactant samples from TA and alveolar surfactant. Several investigators found similar surfactant composition in TA and bronchoalveolar lavage fluid $(23,24)$, but SP-A, SP-B, and SP-C were found to be lower in TA than in lung lavage fluid (23). Of note, surfactant analysis from TA is currently the standard method for the study on surfactant in human research (3).

\section{CONCLUSION}

In conclusion, we describe here a method to measure SP-B kinetics in vivo in humans by stable isotope technology. We were able to obtain kinetic curves in all study infants, including those with severe lung disease. We speculate that this method could be a valuable tool to better understand the role of SP-B in human lung disease.

\section{REFERENCES}

1. Whitsett JA, Weaver TE 2003 Hydrophobic surfactant proteins in lung function and disease. N Engl J Med 347:2141-2148

2. Avery ME 2000 Surfactant deficiency in hyaline membrane disease: the story of discovery. Am J Respir Crit Care Med 161:1074-1075

3. Ballard PL, Merrill JD, Godinez RI, Godinez MH, Truog WE, Ballard RA 2003 Surfactant protein profile of pulmonary surfactant in premature infants. Am J Respir Crit Care Med 168:1123-1128

4. Nogee LM, de Mello DE, Dehner LP, Colten HR 1993 Brief report: deficiency of pulmonary surfactant protein $\mathrm{B}$ in congenital alveolar proteinosis. $\mathrm{N}$ Engl $\mathrm{J}$ Med 328:406-410

5. Ueda T, Ikegami M, Henry M, Jobe AH 1995 Clearance of surfactant protein B from rabbit lungs. Am J Physiol 268:L636-L641

6. Henry M, Ikegami M, Ueda T, Jobe A 1996 Surfactant protein B metabolism in newborn rabbits. Biochim Biophys Acta 1300:97-102

7. Ikegami M, Korfhagen TR, Bruno MD, Whitsett JA, Jobe AH 1997 Surfactant metabolism in surfactant protein A-deficient mice. Am J Physiol 272:L479-L485

8. Cogo PE, Zimmermann LJ, Rosso F, Tormena F, Gamba P, Verlato G, Baritussio A, Carnielli VP 2002 Surfactant synthesis and kinetics in infants with congenital diaphragmatic hernia. Am J Respir Crit Care Med 166:154-158

9. Torresin M, Zimmermann LJ, Cogo PE, Cavicchioli P, Badon T, Giordano G, Zacchello F, Sauer PJ, Carnielli VP 2000 Exogenous surfactant kinetics in infant respiratory distress syndrome: a novel method with stable isotopes. Am J Respir Crit Care Med 161:1584-1589

10. Cogo PE, Carnielli VP, Bunt JE, Badon T, Giordano G, Zacchello F, Sauer PJ, Zimmermann LJ 1999 Endogenous surfactant metabolism in critically ill infants measured with stable isotope labeled fatty acids. Pediatr Res 45:242-246

11. Bligh EG, Dyer WJ 1959 A rapid method of total lipid extraction and purification. Can J Med Sci 37:911-917

12. Schagger H, von Jagow G 1987 Tricine-sodium dodecyl sulfate-polyacrylamide gel electrophoresis for the separation of proteins in the range from 1 to $100 \mathrm{kDa}$. Anal Biochem 166:368-379

13. Metges CC, Petzke KJ, Henning U 1996 Gas chromatography/combustion/isotope ratio mass spectrometric comparison of N-acetyl-and N-pivaloyl amino acid esters to measure $15 \mathrm{~N}$ isotopic abundances in physiological samples: a pilot study on amino acid synthesis in the upper gastro-intestinal tract in minipigs. J Mass Spectrom 31:367-376

14. Husek P 1991 Rapid derivatisation and gas chromatographic determination of amino acids. J Chromatogr B Biomed Appl 552:289-299

15. Baritussio A, Alberti A, Quaglino D, Pettenazzo A, Dalzoppo D, Sartori L, PasqualiRonchetti I 1994 SP-A, SP-B, and SP-C in surfactant subtypes around birth: reexamination of alveolar life cycle of surfactant. Am J Physiol 266:L436-L447

16. Ikegami M, Korfhagen TR, Bruno MD, Whitsett JA, Jobe AH 1997 Surfactant metabolism in surfactant protein A-deficient mice. Am J Physiol 272:L479-L485

17. Melton KR, Nesslein LL, Ikegami M, Tichelaar JW, Clark JC, Whitsett JA, Weaver TE 2003 SP-B deficiency causes respiratory failure in adult mice. Am J Physiol 285:L543-L549

18. Epaud R, Ikegami M, Whitsett JA, Jobe AH, Weaver TE, Akinbi HT 2003 Surfactant protein B inhibits endotoxin-induced lung inflammation. Am J Respir Cell Mol Biol 28:373-378

19. Kerr MH, Paton JY 1999 Surfactant protein levels in severe respiratory syncytial virus infection. Am J Respir Crit Care Med 159:1115-1118

20. Greene KE, Wright JR, Steinberg KP, Ruzinski JT, Caldwell E, Wong WB, Hull W, Whitsett JA, Akino T, Kuroki Y, Nagae H, Hudson LD, Martin TR 1999 Serial changes in surfactant-associated proteins in lung and serum before and after onset of ARDS. Am J Respir Crit Care Med 160:1843-1850

21. Sugahara K, Iyama K, Sano K, Morioka T 1994 Differential expressions of surfactant protein SP-A, SP-B and SP-C mRNA in rats with streptozotocininduced diabetes demonstrated by in situ hybridization. Am J Respir Cell Mol Biol 11:397-404

22. Crouch E, Parghi D, Kuan SF, Persson A 1992 Surfactant protein D: subcellular localization in nonciliated bronchiolar epithelial cells. Am J Physiol 263:L60L66

23. Bernhard W, Haagsman HP, Tschernig T, Poets CF, Postle AD, van Eijk ME, von der Hardt H 1997 Conductive airway surfactant: surface-tension function, biochemical composition, and possible alveolar origin. Am J Respir Cell Mol Biol 17:41-50

24. Rau GA, Dombrowsky H, Gebert A, Thole HH, von der Hardt H, Freihorst J, Bernhard W 2003 Phosphatidylcholine metabolism of rat trachea in relation to lung parenchyma and surfactant. J Appl Physiol 95:1145-1152 